\title{
Student Perceptions Of Faculty Credibility Based On Email Addresses
}

Jeffrey A. Livermore, Walsh College, USA

Marla G. Scafe, Walsh College, USA

Linda S. Wiechowski, Walsh College, USA

\begin{abstract}
The purpose of this study was to evaluate students' perceptions of faculty credibility based on email addresses. The survey was conducted at an upper division business school in Michigan where all students have completed at least two years of college courses. The survey results show that a faculty member's selection of an email address does influence the student's perception of faculty credibility. An email address that consists of a nickname reduces the student's perception of faculty credibility. The reduced creditability may have a negative impact on the faculty member as well as the college.
\end{abstract}

Keywords: faculty credibility, email address, adjunct faculty

\section{INTRODUCTION}

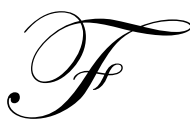

aculty credibility is an important factor in post-secondary education. Credibility is influenced by a number of factors including ethnicity, gender, sexual orientation, and choice of clothing (Morris, Gorham, Cohen \& Huffman 1996; Patton 1999; Russ, Simonds, \& Hunt 2000). Russ, Simonds, and Hunt have proposed that marginalized status may be a factor in how a faculty member's credibility is perceived by students (Russ, Simonds, \& Hunt 2000).

Like many schools, Walsh College relies heavily on adjunct faculty members. Some of these adjunct faculty members use their personal or "day job" email accounts for student communications. The college became concerned that the use of outside email accounts might alter the student's perception of the faculty. The purpose of this study is to evaluate students' perceptions of faculty credibility based on email addresses of faculty.

\section{LITERATURE REVIEW}

Several factors impact the perceived credibility of faculty. According to Morris, Gorham, Cohen, and Huffman, instructor attire impacts the ratings of instructor competence. While they found that the perception of instructor competence was highest for those dressed in formal professional attire, the effect was particularly evident when female students rated female instructors (Morris, Gorham, Cohen \& Huffman 1996). However, Fernandez and Mateo found a slight or non-existent effect of student and faculty gender on teaching quality (Fernandez \& Mateo 1997). Patton studied the impact of ethnicity and gender on instructor credibility. Ethnicity was found to have a significant impact on instructor credibility. The impact of gender on instructor credibility was insignificant (Patton 1999). Glascock and Ruggiero also evaluated the relationship between ethnicity and gender on instructor credibility. While they found little evidence that gender, ethnicity, or a combination of gender and ethnicity had an effect on a student's perception of teacher credibility, they found that both instructor expertise and nonverbal immediacy had an impact on perceived student learning (Glascock \& Ruggiero 2006).

Gender bias appears to exist when students choose their best and worst professors. The bias appears in terms of the male student selecting his best professor. The male student was found to select as his best instructor a male instructor more often than expected. The gender bias was not a factor when male students selected their worst instructor or when female students made their selections ( Basow, Phelan, \& Capotosto 2006). 
An important implication of faculty credibility is student learning. Russ, Simonds and Hunt found that students believed they learned more from the teachers that they considered highly credible. Their study also found that gay teachers are perceived as significantly less credible by their students than straight teachers (Russ, Simonds, \& Hunt 2000).

The use of an email name appears to have an impact on the perceptions of others. Newman, Hebein and Drost surveyed college students about their perceptions of email addresses. They found that a standard business email address was considered more acceptable then either having no email address or using a nickname for an email address (Newman, Hebein, \& Drost 2008). This could be especially important if there is no personal contact with the email recipient such as in online classes.

The purpose of this study is to evaluate students' perceptions of faculty credibility based on email addresses. In some cases, the first correspondence the student has with a professor may be through email. Although it has been found that a student's perception of instructor credibility may change over the course of a semester (McGlone \& Anderson 1973), it may be more difficult for this change to occur if there is no personal contact with the instructor in an online course format. Setting the stage for appropriate credibility will likely be particularly important for online courses.

\section{METHOD}

In setting up this research project, the username and mail service provider were the independent variables and perceived credibility was the dependent variable. The following research hypotheses were evaluated:

H1: Student perception of faculty credibility will be impacted by the domain name used in the email address

H2: Student perception of faculty credibility will be impacted by the use of nicknames in the user name

To test these hypotheses, a survey was created with the NSurvey tool and placed online for two months in 2009. Invitations to take the survey were sent to 1,000 of the currently enrolled students at Walsh College. Walsh is an upper division business school in the northern suburbs of Detroit. The students have all had at least two years of college courses and been exposed to a variety of faculty.

To eliminate gender and name bias, the survey only referred to male names and used the most popular names. The names used were a combination of the most popular first and surnames according to two different sources. The three most popular American surnames were once Smith, Johnson, and Brown (Barker, 1926). According to the Social Security Administration, the three most popular male first names for males in 2007 were Jacob, Michael, and Ethan (SSA 2008).

\section{SURVEY}

The students responded to the following survey questions:

- You are considering taking Professor Jacob Smith for a section of the "Introduction to Technology" course that is a requirement for your major field of study. Based on his email address of MrBaseball@EDS.com, how credible do you feel Professor Smith is? Please rate Professor Smith's credibility on a scale ranging from not credible to extremely credible (not credible, credible, extremely credible, no opinion).

- You are considering taking Professor Michael Johnson for a section of the "Introduction to Technology" course that is a requirement for your major field of study. Based on his email address of Michael.Johnson@aol.com, how credible do you feel Professor Johnson is? Please rate Professor Smith's credibility on a scale ranging from not credible to extremely credible (not credible, credible, extremely credible, no opinion). 
- You are considering taking Professor Ethan Brown for a section of the "Introduction to Technology" course that is a requirement for your major field of study. Based on his email address of Ethan.Brown@EDS.com, how credible do you feel Professor Johnson is? Please rate Professor Smith's credibility on a scale ranging from not credible to extremely credible (not credible, credible, extremely credible, no opinion).

- You are considering taking Professor Jacob Johnson for a section of the "Introduction to Technology" course that is a requirement for your major field of study. Based on his email address of Jacob.Smith@WalshCollege.edu, how credible do you feel Professor Johnson is? Please rate Professor Smith's credibility on a scale ranging from not credible to extremely credible (not credible, credible, extremely credible, no opinion).

- You are considering taking Professor Jacob Johnson for a section of the "Introduction to Technology" course that is a requirement for your major field of study. Based on his email address of MrBaseball@aol.com, how credibledo you feel Professor Johnson is? Please rate Professor Smith's credibility on a scale ranging from not credible to extremely credible (not credible, credible, extremely credible, no opinion).

- You are considering taking Professor Jacob Johnson for a section of the "Introduction to Technology" course that is a requirement for your major field of study. Based on his email address of MrFootball@WalshCollege.edu, how credible do you feel Professor Johnson is? Please rate Professor Smith's credibility on a scale ranging from not credible to extremely credible (not credible, credible, extremely credible, no opinion).

\section{RESULTS}

The respondents were mostly female (91), with 62 male respondents and six respondents who preferred not to provide their gender. More of the respondents were graduate students (82) rather than undergraduates (68) which was expected as Walsh is primarily a graduate school with $55 \%$ of the student population being graduate students.

Survey results were obtained for each scenario presented to Walsh College students and are as follows:

Table 1: Summarized Survey Results

\begin{tabular}{|l|c|c|c|c|c|}
\hline Email Account & $\begin{array}{c}\text { Extremely } \\
\text { Credible }\end{array}$ & Credible & $\begin{array}{c}\text { Not } \\
\text { Credible }\end{array}$ & No Opinion & Total \\
\hline Full name at walshcollege.edu & 84 & 52 & 0 & 21 & 157 \\
\hline Full name at EDS.com & 35 & 90 & 12 & 22 & 159 \\
\hline Full name at aol.com & 4 & 95 & 26 & 34 & 159 \\
\hline Nickname at EDS.com & 3 & 48 & 76 & 32 & 159 \\
\hline Nickname at walshcollege.edu & 3 & 47 & 82 & 27 & 159 \\
\hline Nickname at aol.com & 0 & 26 & 100 & 32 & 158 \\
\hline
\end{tabular}

The detailed results for each question are as follows:

Scenario one: Mr.Baseball@EDS.com: 76 or $47.8 \%$ evaluated this email address as not credible, 48 or $30.19 \%$ thought it was credible. Only three thought it was extremely credible and $20.13 \%$ had no opinion. More students felt that this email address was not credible compared with those that found it to be credible. A Chi-square Goodness of Fit test showed a significant difference in credibility rankings (Chi-sq= 70.2579, $\mathrm{p}=.000)$.

Scenario Two: Michael.Johnson@aol.com: 26 or 16.35\% evaluated this email address as not credible as opposed to 95 or $59.75 \%$ who viewed this address as credible. Four responded that it was extremely credible and $21.38 \%$ had no opinion. Almost $60 \%$ of the respondents viewed this email address as credible as opposed to $30 \%$ for the first scenario. The Chi-square Goodness of Fit test showed a significant difference in credibility rankings (Chi$\mathrm{Sq}=114.535, \mathrm{p}=.000)$. 
Scenario Three: Ethan.Brown@EDS.com: Only 12 or $7.55 \%$ of the respondents evaluated this email address as not credible. 90 or 56.60 thought this person was credible and 35 or $22.01 \%$ thought he was an extremely credible source. Only $13.84 \%$ had no opinion. A Chi-Square Goodness of Fit test showed a significant difference in the rankings (Chi-sq. $=91.3899, \mathrm{p}=.000$ ). So far, this email address was judged by students to be the most credible because it contains a popular male name rather than a nickname and it is from a work email (EDS) as opposed to aol. EDS was purposely chosen for a technology course because EDS is a technology oriented organization.

Scenario Four: Jacob.Smith@walshcollege.edu: No one (0) judged this email address to have no credibility. 52 or $33.12 \%$ found it to be credible and 84 or $53.50 \%$ evaluated it as being extremely credible with 13.38 having no opinion. This is by far the most credible email combining a popular and credible male name with a college email address. Using a college email address lends the most credibility to a faculty member. A Chi-square Goodness to Fit test showed significant difference in the rankings $($ Chi-sq $=37.9236, p=.000)$

Scenario Five: Mr.Baseball@aol.com: 100 or 63.29\% judged this individual's email address to be not credible. This is the highest "not credible" ranking so far. Only 26 or $16.46 \%$ found it to be credible and no one (0) ranked it as extremely credible with 20.25 again having no opinion. A Chi-square Goodness to Fit test showed a significant difference in the rankings (Chi-sq= 64.1519, $\mathrm{p}=.000)$.

Scenario Six: Mr.Football@walshcollege.edu: Even though walshcollege was used as the email address, the fact that the name was Mr.Football created some doubts in the students' minds as to this person's credibility. 82 or $51.57 \%$ evaluated this email address as not credible, the second most "not credible" email address. 47 or 29.56 judged it to be credible and only three said it was extremely credible with $16.98 \%$ having no opinion. A Chi-square Goodness of Fit test revealed that the rankings were significantly different (Chi-sq. $=84.2956, \mathrm{p}=.000$ ).

Chi-Square test of independence tests were performed on all of the six email scenarios broken down by gender and class (undergraduate versus graduate). In each case, the Chi-squares were not significantly different, illustrating that these judgments of credibility levels are independent of gender and class and hence they were judged the same regardless of gender or class.

\section{CONCLUSION}

It has been found at Walsh College that the faculty member's email address is an important factor determining faculty credibility. Faculty credibility is important for a variety of reasons. The lack of credibility may have a negative impact on faculty in a variety of ways. First, it may result in lower student evaluations. This may impact a faculty member's pay and course load. This could be especially true for adjunct faculty that work on a semester by semester contract. Full-time faculty may be negatively impacted with lower performance reviews, resulting in lower pay. The reduced credibility may have a negative impact on the promotion and tenure decisions of the faculty member.

The lack of credibility has been linked to perceived learning (Russ, Simonds, \& Hunt 2000; Glascock \& Ruggiero 2006). As many colleges are struggling with increased competition, student satisfaction is important. A lack of perceived learning may reduce a student's satisfaction, resulting in a decrease in enrollments.

It is important for colleges and faculty to be aware that the use of an email address may negatively impact a faculty member's credibility. While many faculty have the ability to use a variety of email addresses, it may be in the best interest of both college and the faculty members to restrict all email correspondence with students to a college assigned email address that consists of some form of the faculty member's first and last names.

\section{AUTHOR INFORMATION}

Jeffrey A. Livermore, Ph.D., is an Associate Professor at Walsh College. He teaches in the BIT, Information Assurance, and Doctorate of Management programs and is currently researching the ethics of teaching information security. He can be reached at jlivermore@walshcollege.edu. 
Marla G. Scafe, Ph.D., has been a faculty member at Walsh College for over 25 years teaching Quantitative Methods and Research at the undergraduate, masters, and doctoral levels. She has also been a consultant-evaluator for the Higher Learning Commission of North Central Association for over 15 years. Her research interests center around the use of group testing with adult learners.

Linda S. Wiechowski, Ph.D., earned a bachelor degree in accounting from Walsh College. She also holds a Masters in Business Administration and a PhD in Economics, both from Wayne State University. She has been teaching finance and economics courses at Walsh College for over 20 years. Her research interests include a variety of corporate finance topics, health economics, and the integration of online technology in all levels of education. She has presented "Best Practices in Online Education" at a variety of conferences.

\section{REFERENCES}

1. $\quad$ Barker, H. (1926), Our leading surnames. American Speech. 1(9), 470-477.

2. Basow, S. A., Phelan, J. E., \& Capotosto, L. (2006). Gender patterns in college students' choices of their best and worst professors. Psychology of Women Quarterly, 30, 25 - 35.

3. Fernandez, J. \& Mateo, M. A. (1997). Student and faculty gender in ratings of university teaching quality. Sex Roles, 37, $997-1003$.

4. Glascock, J., \& Ruggiero, T. E. (2006). The relationship of ethnicity and sex to professor credibility at a culturally diverse university. Communication Education, 55, 197 - 207.

5. McGlone, E. L., \& Anderson, L. J. (1973). The dimensions of teacher credibility. The Speech Teacher, 23, $196-200$.

6. Morris, T., Gorham, J., Cohen, S. \& Huffman, D. (1996). Fashion in the classroom: Effects of attire on student perception of Instructors in college classes. Communication Education. 45(2), 135-148.

7. Newman, E., Hebein, F. \& Drost, D. (2008). The perception of an email name. International Journal of Global Business and Economics, Vol. 1, No. 1.

8. Patton, T. (1999). Ethnicity and gender: An examination of its impact on instructor credibility in the university classroom. Howard Journal of Communication. 10(2), 123-144.

9. Russ, T., Simonds, C., Hunt, S. (2002). Coming out in the classroom...An occupational hazard?: The influence of sexual orientation on teacher credibility and perceived student learning. Communication Education. 31(3), 311-324.

10. SSA (2008, May 19). Popular Baby Names. Retrieved July, 2008 from http://www.ssa.gov/OACT/babynames/ 
NOTES 